Polymer Journal, Vol. 39, No. 6, pp. 531-536 (2007)

(C) 2007 The Society of Polymer Science, Japan

\title{
Preparation of Polyglycidol/SiO 2 Hybrid Films with Triethoxysilyl-Capped Poly(ethylene glycol)
}

\author{
Bong-Soo KIM, ${ }^{1}$ Ji-Sun IM, ${ }^{1}$ Seung-Tae BAEK, ${ }^{1}$ Jang-Oo LEE,,${ }^{1, \dagger}$ \\ Tsuyoshi KaWASHIMA, ${ }^{2}$ and Kohji YoshinaGA ${ }^{2}$ \\ ${ }^{1}$ Division of Chemical Engineering, Pusan National University, 30 Jangjeon-dong, \\ Geumjeong-gu, Busan 609-735, Republic of Korea \\ ${ }^{2}$ Department of Applied Chemistry, Kyushu Institute of Technology, Sensui, Tobata, Kitakyushu 804-8550, Japan
}

(Received August 22, 2006; Accepted March 4, 2007; Published April 17, 2007)

\begin{abstract}
The preparation and properties of polyglycidol (PGLD)/silica hybrid gels were investigated. The gels were synthesized by the reaction of hyperbranched PGLD and triethoxysilyl-capped poly(ethylene oxide) in the presence of colloidal silica $80 \mathrm{~nm}$ in size or tetraethyl orthosilicate (TEOS) under acidic circumstances. The crosslinking reaction gave hybrid gels with a relatively high gel fraction over $98 \%$. The degree of gel swelling obtained by the reaction using colloidal silica and TEOS decreased with $\mathrm{SiO}_{2}$ content, while the stiffness of the gels increased with $\mathrm{SiO}_{2}$ content. Gels prepared from TEOS exhibited a swelling ratio ranging from $25 \%$ to $40 \%$, which was relatively higher than those from colloidal silica. They also demonstrated a higher stiffness in comparison to those from colloidal silica, probably due to high crosslinking. [doi:10.1295/polymj.PJ2006098]

KEY WORDS Polyglycidol / Silica / Hybrid Films / Hybrid Hydrogel / TEOS /
\end{abstract}

In recent years, there has been an increased interest in hyperbranched polymers and their applications. ${ }^{1-7}$ Polyglycidol (PGLD) is a flexible hydrophilic aliphatic polyether polyol that can be prepared in hyperbranched, branched or linear forms. Hyperbranched polymers, rather than linear polymers, have advantages in easy formation of network structures. ${ }^{8}$ Thus, hyperbranched polymers have a large number of functional groups that may have desirable chemical properties, including enhanced compatibility with inorganic and/or organic materials or biomaterials. Among them, PGLD has gained attention because it contains hydroxyl groups in repeating units which allows for chemical modification or conversion to other groups in order to prepare functional polymers. ${ }^{9} \mathrm{Be}-$ cause of the structural similarities with poly(ethylene glycol) (PEG), one of the most studied widely used biocompatible polymers in the pharmaceutical and biomedical fields, PGLD is also expected to be biocompatible. $^{10,11}$ Moreover, hydrogels from PGLD composed of glycerin units have a large water content due to their hydrophilicities. They also possess potential applications in biodegradability, and food additives. $^{2,3,12}$ Therefore, we have investigated the routes of synthesis and properties of PGLD hydrogel films prepared using crosslinking agents such as glutaldehyde, several dicarboxylic acids ${ }^{13}$ and carboxyl-terminated poly(ethylene glycol) ${ }^{14}$ for more applications. The crosslinked PGLD hydrogel films obtained from our previous work exhibited considerably enhanced mechanical properties while maintaining greater water content. Therefore, incorporation of PGLD hydrogel into ion exchangeable segments such as silanol is promising for application of a new material of ion transfer or exchange gel. ${ }^{15-21}$

In this study, we have prepared the PGLD/silica hybrid films from two different $\mathrm{SiO}_{2}$ sources, colloidal silica $(80 \mathrm{~nm})$ and TEOS, using the oligomeric crosslinking agent (triethoxysilyl-capped poly(ethylene glycol)) PEG-silane. Then we investigated the swelling behavior and mechanical properties for both types of silica hybrids with the aim of enhancing structural strength and toughness by incorporating silica within the organic matrix.

\section{EXPERIMENTAL}

\section{Materials}

Glycidol (Wako Pure Chem., Japan) was distilled under reduced pressure prior to use. Diglycerin and TEOS were obtained from Kashima Chem., Japan and TCI Chem., Japan respectively. 3-Isocyanatepropyltriethoxysilane was purchased from Shinetsu Chem., Japan. Magnesium, sodium, poly(ethylene glycol) $\left(M_{\mathrm{n}}=200\right)$, benzene, hexane, ethanol and chloroform were obtained from Wako Pure Chem., Japan.

\section{Synthesis of Polyglycidol}

PGLD was synthesized by direct anion ring-opening polymerization of unprotected glycidol according to the following procedure. ${ }^{13} \mathrm{~A}$ two-necked flask was charged under argon with sodium; distilled ethanol

${ }^{\dagger}$ To whom correspondence should be addressed (Tel: +82-51-510-2404, Fax: +82-51-513-7720, E-mail: leejo@ pusan.ac.kr). 
was cautiously added. The reaction mixture was stirred at ambient temperature until the sodium completely reacted. A solution of diglycerin in distilled ethanol was then added and heated to $120^{\circ} \mathrm{C}$ under reduced pressure. After removing the ethanol, the initiator was obtained.

A typical polymerization procedure was as follows: the initiator was taken under argon atmosphere in a two-necked flask. Glycidol was added at a rate of $0.1 \mathrm{~mL} / \mathrm{min}$ with stirring; the polymerization was then initiated. Following completion of polymerization, unreacted glycidol was removed after stirring for 30 min at $120^{\circ} \mathrm{C}$ under reduced pressure; hyperbranched PGLD was finally obtained as a viscous liquid.

\section{Synthesis of the Crosslinking Agent (Triethoxysilyl- Capped PEG)}

We are able to introduce a silyl group into the end group of PEG with a molecular weight of 200. PEG and benzene were placed in a two-necked flask and azeotropically distilled at $90^{\circ} \mathrm{C}$. Then, chloroform and 3-isocyanatepropyltriethoxysilane were added under nitrogen charge and stirred for $12 \mathrm{~h}$ at $60^{\circ} \mathrm{C}$. Chloroform was removed by evaporation. After adding hexane, unreacted 3-isocyanatepropyltriethoxysilane was removed and then hexane was removed by evaporation. The products were structure-analyzed using a ${ }^{1} \mathrm{H}$ NMR spectroscope.

\section{Preparation of the PGLD/Silica Hybrid Film}

PGLD/silica hybrid films were prepared using two types of silica; colloidal silica $(80 \mathrm{~nm})$ and TEOS. $0.1 \mathrm{~N} \mathrm{HCl}$ was added as an acid catalyst to an aqueous solution in which PGLD, the crosslinking agent (PEGsilane), and colloidal silica or TEOS were dissolved. The above solution was cast on polyethylene substrate and covered with a Teflon sheet. The solution was then heated at $40^{\circ} \mathrm{C}$ until the water completely vaporized. After drying at $80^{\circ} \mathrm{C}$ for $12 \mathrm{~h}, \mathrm{PGLD} /$ silica hybrid films were obtained. The PGLD/silica hybrid films prepared from colloidal silica and TEOS are denoted in Table I.

\section{Measurements}

${ }^{1} \mathrm{H}$ NMR spectra were obtained at $400 \mathrm{MHz}$ on a Bruker AVANCE-400 using $\mathrm{D}_{2} \mathrm{O}$ as a solvent. Solid state ${ }^{13} \mathrm{C}$ and ${ }^{29} \mathrm{Si} \mathrm{CP} / \mathrm{MAS}$ NMR spectra were recorded on a Bruker AVANCE-300 using a $7 \mathrm{~mm}$ probe. Molecular weight $\left(M_{\mathrm{w}}\right)$ of prepared PGLD was estimated by gel permeation chromatography (GPC) based on calibration with a polyethylene glycol standard. Water was used as the mobile phase at a flow rate of $0.5 \mathrm{~mL} / \mathrm{min}$. The gel fraction (as a measure of the degree of gelation) of the PGLD/silica hybrid film was determined by extraction with distilled
Table I. The list of PGLD/silica hybrid films

\begin{tabular}{lcccc}
\hline Sample & $\begin{array}{c}\text { PGLD } \\
(\mathrm{g})\end{array}$ & $\begin{array}{c}\text { PEG-Silane } \\
(\mathrm{g})\end{array}$ & $\begin{array}{c}\text { Colloidal silica } \\
(\mathrm{wt} \%)\end{array}$ & $\begin{array}{c}\text { TEOS } \\
(\mathrm{wt} \%)\end{array}$ \\
\hline CS-0 & 0.3 & 0.9 & 0.0 & - \\
CS-1.0 & 0.3 & 0.9 & 1.0 & - \\
CS-2.5 & 0.3 & 0.9 & 2.5 & - \\
CS-5.0 & 0.3 & 0.9 & 5.0 & - \\
CS-7.5 & 0.3 & 0.9 & 7.5 & - \\
CS-10 & 0.3 & 0.9 & 10.0 & - \\
\hline TEOS-0 & 0.3 & 0.9 & - & 0.0 \\
TEOS-1.0 & 0.3 & 0.9 & - & 1.0 \\
TEOS-2.5 & 0.3 & 0.9 & - & 2.5 \\
TEOS-5.0 & 0.3 & 0.9 & - & 5.0 \\
TEOS-7.5 & 0.3 & 0.9 & - & 7.5 \\
TEOS-10 & 0.3 & 0.9 & - & 10.0 \\
\hline
\end{tabular}

water. The resultant PGLD/silica hybrid films obtained via crosslinking reactions were weighed after drying. They were then immersed in distilled water and extracted. After subsequent drying, extracted samples were weighed. The gel fraction was calculated using the following relationship:

$$
\text { Gel fraction }(\%)=\frac{W}{W_{0}} \times 100
$$

where $W_{o}$ and $W$ were the weights of dried sample before extraction and after extraction, respectively. ${ }^{22,23}$ The water content of the PGLD/silica hybrid films after swelling was investigated as follows. The samples were immersed in distilled water. The sufficiently swollen films were weighed. After drying, the samples were re-weighed. The equilibrium degree of swelling was calculated according to the following equation:

Equilibrium degree of swelling (\%)

$$
=\frac{\left(W_{s}-W_{d}\right)}{W_{d}} \times 100
$$

where $W_{s}$ and $W_{d}$ denote the weights of dried and swollen PGLD/silica hybrid films, respectively. Observation of the dried PGLD/silica hybrid films was carried out with an increase in concentration of colloidal silica and TEOS. The Young's moduli of the hybrid films were measured using a thermal mechanical analyzer (TMA) at an extension rate of $50 \mathrm{~mm} / \mathrm{min}$ on a Shimadzu TMA-50. After drying in a drying oven for $24 \mathrm{~h}$ at room temperature to remove residual water, strip-shaped specimens with dimensions of $20 \times 4 \mathrm{~mm}$ and thickness of approximately $1.5 \mathrm{~mm}$ were used for the tensile test at $25^{\circ} \mathrm{C}$.

\section{RESULTS AND DISCUSSION}

Hyperbranched PGLD was synthesized via direct anion ring-opening polymerization of unprotected glycidol, confirmed by ${ }^{1} \mathrm{H}$ NMR spectroscope in our pre- 


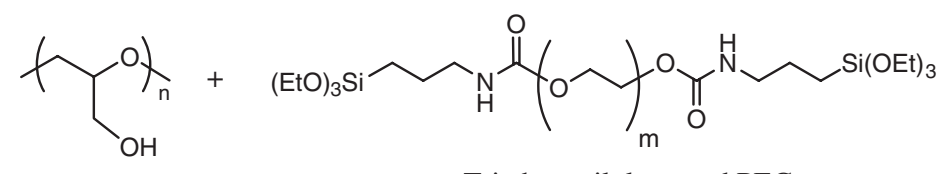

PGLD

Triethoxysilyl-capped PEG

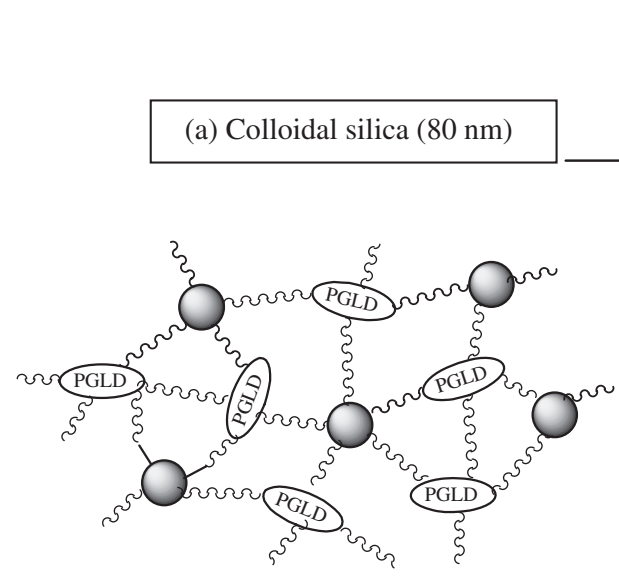

(a) $\mathrm{PGLD} / \mathrm{SiO}_{2}$ from colloidal silica
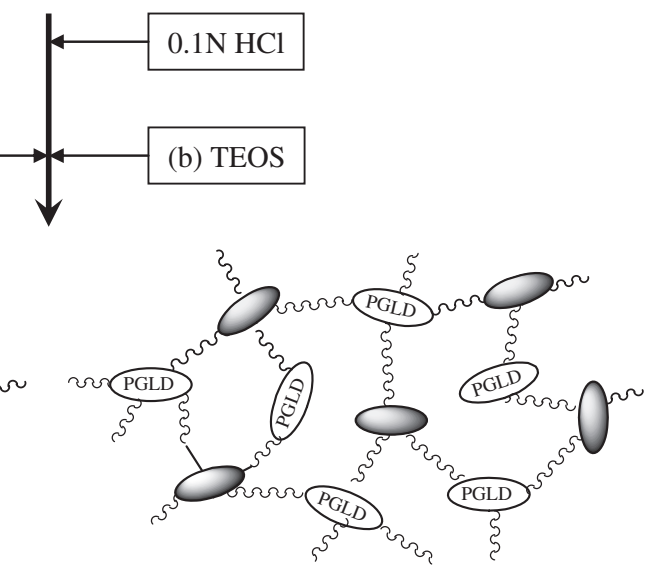

(b) $\mathrm{PGLD} / \mathrm{SiO}_{2}$ from TEOS
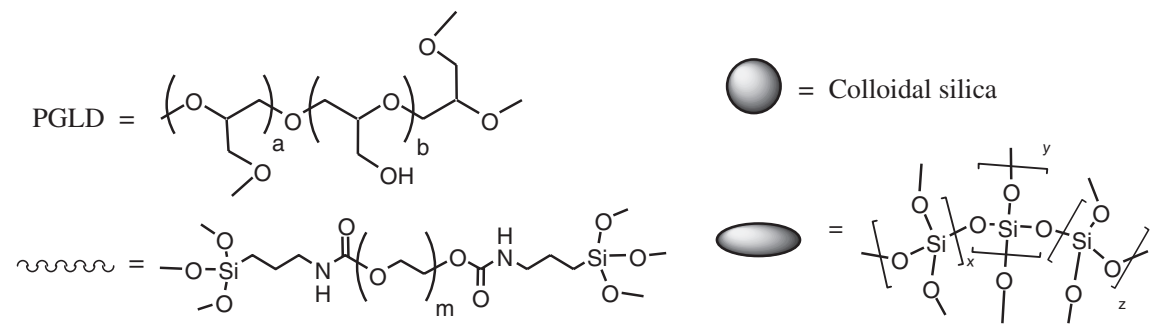

Scheme 1. Preparation of $\mathrm{PGLD} / \mathrm{SiO}_{2}$ hybrid films prepared with colloidal silica and TEOS.

vious work. ${ }^{13,14}$ The resultant PGLD was a transparent and light yellow syrup; its average molecular weight $\left(M_{\mathrm{n}}\right)$ and polydispersity as determined by GPC were 1161 and 1.81, respectively. The triethoxysilyl-capped PEG (PEG-silane), used as a crosslinkilng agent, was obtained by reacting PEG with 3-isocyanatepropyl triethoxysilane at $60^{\circ} \mathrm{C}$ for $12 \mathrm{~h}$; this was confirmed by the ${ }^{1} \mathrm{H}$ NMR spectrum. Next, PGLD/silica hybrid films were successfully prepared using two types of silica; colloidal silica and TEOS, with various compositions based on the mechanism as sketched in Scheme 1. PEG-silane plays an important role in this system; its primary role as a crosslinking agent is to initiate the crosslinking reaction through a reaction between the hydroxyl groups of hyperbranched PGLD and the triethoxysilyl groups of PEG-silane. Its secondary role is to chemically connect the organic matrix (PGLD) and inorganic material (silica) as a coupling agent.

Figure 1 shows the ${ }^{13} \mathrm{C} \mathrm{CP} / \mathrm{MAS}$ NMR spectra of dried PGLD $/ \mathrm{SiO}_{2}$ hybrid gels composed of $0.3 \mathrm{~g}$ PGLD, 0.9 g PEG-silane and $5.0 \mathrm{mg} \mathrm{SiO}_{2}$ prepared from colloidal silica and TEOS. In both cases reso-

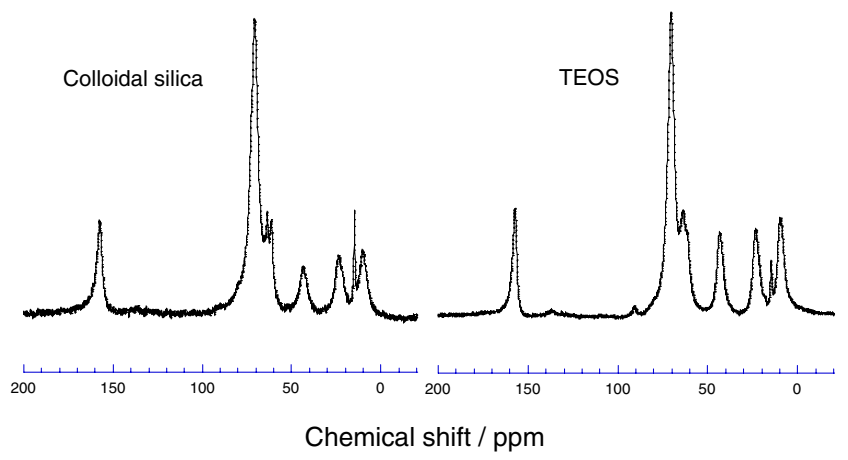

Figure 1. ${ }^{13} \mathrm{C} \mathrm{CP} / \mathrm{MAS} \mathrm{NMR}$ spectra of dried $\mathrm{PGLD} / \mathrm{SiO}_{2}$ hybrid films prepared with colloidal silica and TEOS.

nance peaks at 8-15 $\left(\mathrm{Si}-\mathrm{CH}_{2}-\right.$ and $\left.\mathrm{CH}_{2} \mathrm{CH}_{2} \mathrm{CH}_{2}\right)$, 20-30 ( $\left.\mathrm{CH}_{3} \mathrm{CH}_{2} \mathrm{OSi}-\right)$, 35-45 $\left(\mathrm{CH}_{2} \mathrm{NH}-, \mathrm{CH}_{3} \underline{\mathrm{CH}}_{2}-\right.$ OSi-), 60-80 (=ㄷH-O-, $\left.\mathrm{CHCH}_{2} \mathrm{O}\right)$, and 155-160 $(\mathrm{O}(\underline{\mathrm{C}}=\mathrm{O}) \mathrm{NH}) \mathrm{ppm}$ were observed.

${ }^{29} \mathrm{Si} \mathrm{CP} / \mathrm{MAS}$ NMR spectra of the hybrid gels are shown in Figure 2. The resonance peaks at -100 and $-110 \mathrm{ppm}$ were assignable to silicons of $\mathrm{Q}^{3}$ and $\mathrm{Q}^{4} .^{24,25}$ It was observed that the gel prepared from TEOS was composed of less $\mathrm{SiO}_{2}$ than that from col- 


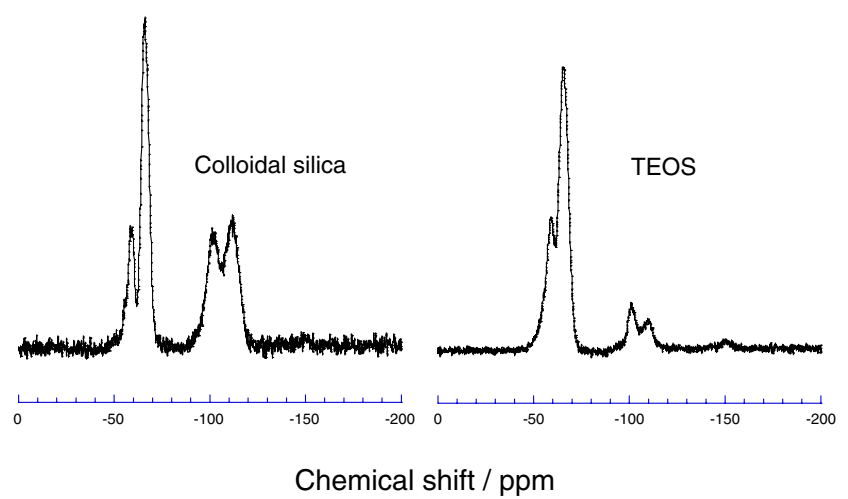

Figure 2. ${ }^{29} \mathrm{Si} \mathrm{CP} / \mathrm{MAS} \mathrm{NMR}$ spectra of dried $\mathrm{PGLD} / \mathrm{SiO}_{2}$ hybrid films prepared with colloidal silica and TEOS.

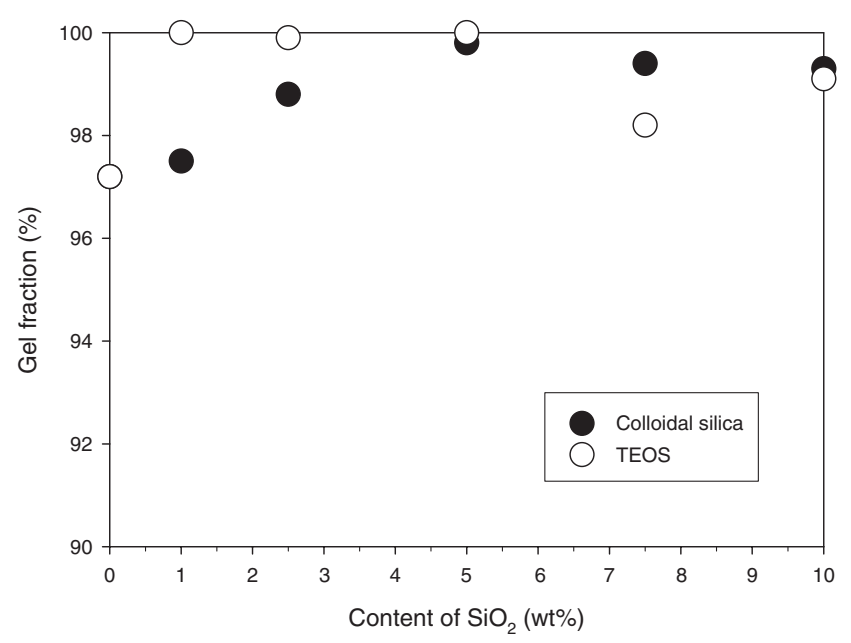

Figure 3. Effect of the silica content on the gel fraction of PGLD/silica hybrid films with constant polymer and crosslinking agent $([\mathrm{PGLD}] /[\mathrm{PEG}-$ Silane $]=1 / 3)$.

loidal silica. According to the literature values of ${ }^{29} \mathrm{Si}$ chemical shifts, ${ }^{26}$ resonance peaks at -60 and -70 ppm were assigned to silicons $\left(\mathrm{CH}_{2}\right.$-Si-O-) formed by the reaction of PEG-silane with silanol or hydroxyl groups. Therefore, it was confirmed that PGLD, PEG and $\mathrm{SiO}_{2}$ components bounded via $\mathrm{Si}-\mathrm{O}-\mathrm{SiCH}_{2}$-bonds to form a gel. These results indicate that gels obtained by cross-linking reactions using TEOS are composed of mostly the same chemical structure as those formed using colloidal silica.

Both gel fractions and equilibrium degrees of swelling for PGLD/silica hybrid films prepared with different silica contents were measured to estimate the extent of crosslinking and water content. As shown in Figure 3, gel fractions of hybrid films were more than $97 \%$, irrespective of the type and concentration of silica. These values of gel fractions are higher than those of pure PGLD films as noted in previous work. ${ }^{13,14}$ That suggested that PGLD and PEG-silane were completely and strongly crosslinked in comparison to pure PEG and glutaric acid. Swelling behavior

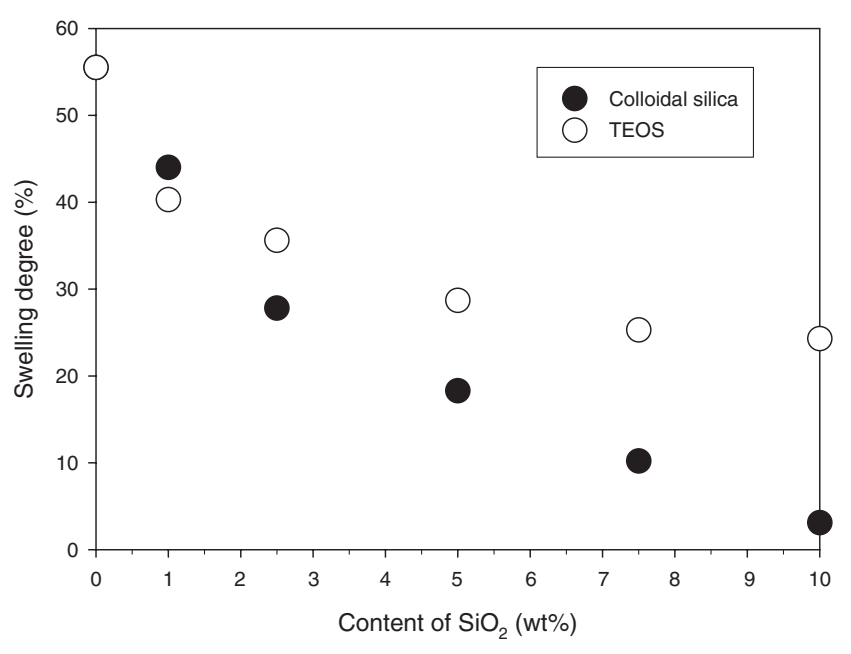

Figure 4. Effect of the silica content on the degree of swelling of PGLD/silica hybrid films with constant polymer and crosslinking agent $([\mathrm{PGLD}] /[\mathrm{PEG}-$ Silane $]=1 / 3)$.

of hybrid films was investigated via the measurement of mass changes in the samples under static conditions.

Figure 4 shows the values of the equilibrium degree of swelling for PGLD/silica hybrid films. As expected, the degree of swelling of hybrid films decreased with the silica content. This may be because introduction of the PEG-silane and silica resulted in an increase in the crosslinking density, thereby impeding the diffusion of water molecules into the polymer network. Moreover, as shown in Figure 4, the degree of swelling of the hybrid films containing colloidal silica decreased remarkably compared to that of hybrid films from TEOS. When employing TEOS, a threedimensional crosslinked inorganic network structure formed by the sol-gel process of TEOS can be developed in situ within a polymer matrix as well as by the crosslinking of PGLD and PEG-silane. In contrast with TEOS, colloidal silica with PEG-silane can be extensively bridged between polymer chains but can not form a dense inorganic and organic network structure. These factors also affect mechanical properties of hybrid films. However, swelling is usually controlled by a balance between osmotic pressure and tension of the network in a gel. Generally speaking, tension increases with the amount of crosslinking in the gel. In addition, osmotic pressure increases with the solvation or affinity between the polymer chains and water molecules, which is directly proportional to total length of the hydrophilic polymer chains. In the case of gel prepared from TEOS, total length of the polymer chains including PGLD, PEG-silane seemed to be much longer, as compared with that in gel from colloidal silica. On the other hand, gel prepared from colloidal silica might show high tensions in gels but have lower osmotic pressures. As a result, gel pre- 
(a)

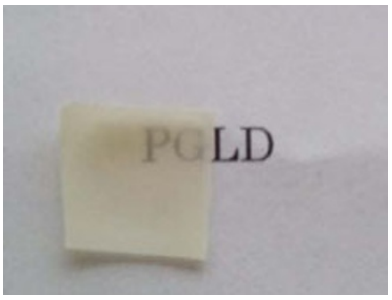

(c)

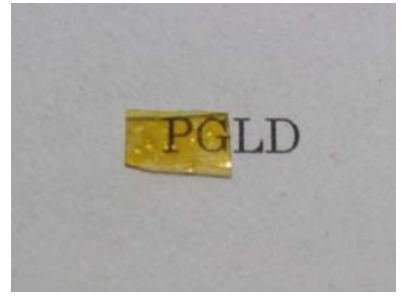

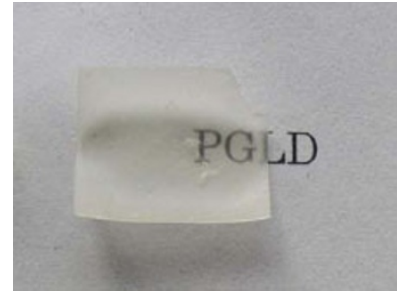

(b)

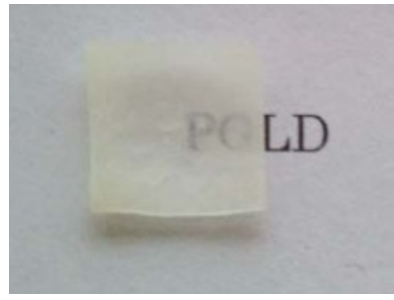

(d)
Figure 5. Images of PGLD/silica hybrid films with various concentrations of colloidal silica: (a) CS-0; (b) CS-2.5; (c) CS5.0; (d) CS-7.5.

pared using TEOS probably shows higher osmotic pressures to give a swelling degree much more than that from colloidal silica.

Figure 5 shows dried PGLD/silica hybrid films increasing in concentrations of colloidal silica. Transparency of the dried PGLD/silica hybrid films decreased with increasing concentrations of colloidal silica. Moreover, transparency is much lower in comparison with PGLD/silica hybrid films obtained from TEOS, as shown in Figure 6. This is due to the size of the silica particles in PGLD/silica hybrid films. The size of silica in PGLD/silica hybrid films with colloidal silica is bigger than those from TEOS. The particles of silica in PGLD/silica hybrid films cause light to scatter.

From Figure 7, we can see that Young's modulus of hybrid films was increased remarkably with an increase of silica content. This may indicate significant structural strength and stiffness via incorporation of PEG-silane and silica within the PGLD matrix which was obtained from enhanced chemical crosslinking, as inferred from the gel fraction. In particular, the values of Young's modulus of hybrid films using TEOS were higher than those for hybrid films containing colloidal silica, similar to the swelling behavior. As stated before, this may result from enhanced stiffness which was from incorporation of the inorganic network structure via the sol-gel process within the PGLD matrix, in addition to crosslinking by PEG-silane. This is in contrast to the case of colloidal silica. As a reference, these values of Young's modulus of PGLD/ silica hybrid films are much higher than those of pure PGLD hydrogel films in our previous work. ${ }^{13,14}$ This

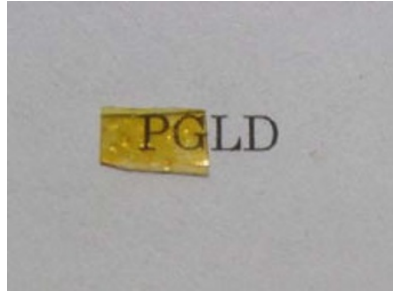

(a)

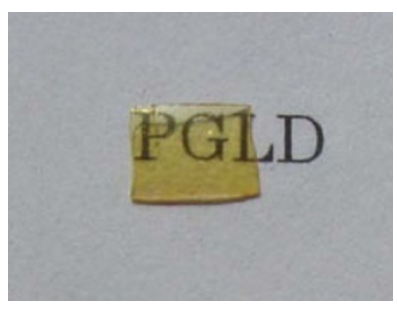

(c)

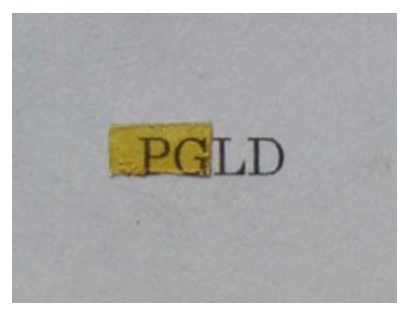

(b)

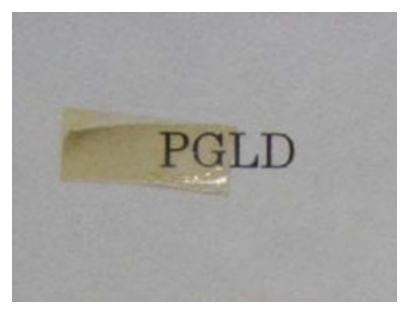

(d)
Figure 6. Images of PGLD/silica hybrid films with various concentrations of TEOS: (a) TEOS-0; (b) TEOS-2.5; (c) TEOS5.0; (d) TEOS-7.5.

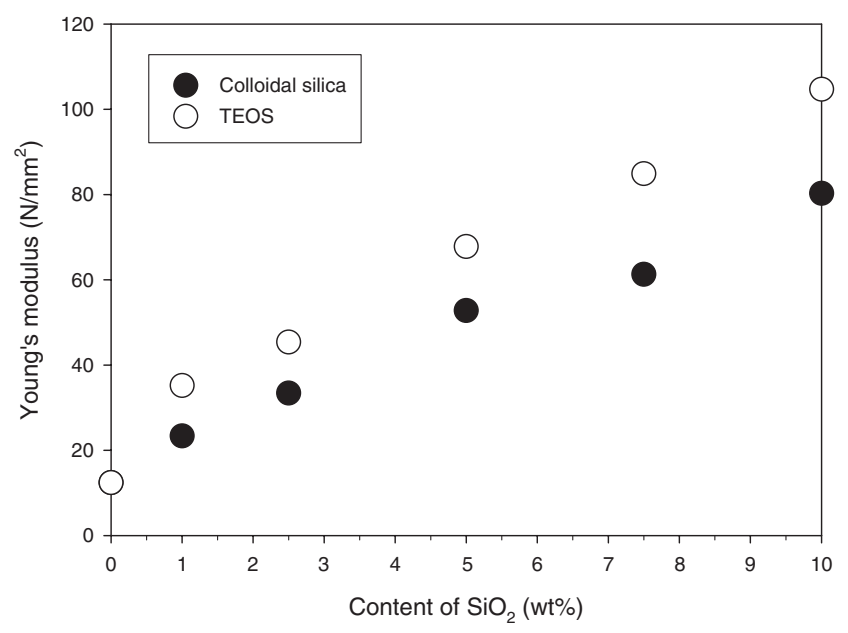

Figure 7. The Young's modulus of PGLD/silica hybrid films as a function of the silica content with constant polymer and crosslinking agent ([PGLD]/[PEG-Silane] $=1 / 3)$.

is attributable to the increased elasticity resulting from enhanced chemical crosslinking and the inorganic network structure caused by the introduction of silica as a crosslinking agent within the PGLD matrix.

\section{CONCLUSIONS}

PGLD/silica hybrid films were successfully prepared using two types of silica-colloidal silica and TEOS. The incorporated silica was chemically crosslinked with PGLD using triethoxysilyl-capped PEG (PEG silane), thereby providing the hybrid films with remarkable stiffness with retention of a higher water content. In particular, PGLD/silica hybrid films from 
TEOS exhibited considerably enhanced stiffness by incorporating an inorganic network structure via the sol-gel process within the organic (PGLD) matrix.

Acknowledgment. This work was supported, in part, by grant No. R01-2003-000-11612-0 from the Basic Research Program of the Korea Science \& Engineering Foundation.

\section{REFERENCES}

1. R. K. Kainthan, J. N. Kizhakkedathu, and D. E. Brooks, Macromol. Chem. Phys., 205, 567 (2004).

2. E. J. Vandenberg, J. Polym. Sci., Polym. Chem. Ed., 23, 915 (1985).

3. W. Walach, A. Kowalczuk, B. Trzebicka, and A. Dworak, Macromol. Rapid Commun., 22, 1272 (2001).

4. R. Tokar, P. Kubisa, and S. Penczek, Macromolecules, 27, 320 (1994).

5. A. T. Royappa, M. L. Vogt, and V. Sharma, J. Appl. Polym. Sci., 91, 1344 (2004).

6. X. Wang, Polym. Prepr. (Am. Chem. Soc., Div. Polym. Chem.), 42(2), 381 (2001).

7. M. Khan and W. Huck, Macromolecules, 36, 5088 (2003).

8. A. Hult, E. Malmstrom, and M. Johansson, in "Polymeric Materials Encyclopedia,” J. C. Salamone, Ed., CRC press, New York, 1996, Vol. 5.

9. A. L. Borgne, N. Spassky, and D. Taton, in "Polymeric Materials Encyclopedia,” J. C. Salamone, Ed., CRC press, New York, 1996, Vol. 8.

10. H. Frey and R. Haag, Rev. Mol. Biotechnol., 90, 257 (2002).

11. C. Siegers, M. Biesalski, and R. Haag, Chem. Eur. J., 10,
2831 (2004).

12. D. Tanton, A. L. Borgne, M. Sepulchre, and N. Spassky, Macromol. Chem. Phys., 195, 139 (1994).

13. B. S. Kim, J. S. Im, S. T. Baek, J. O. Lee, Y. Azuma, and K. Yoshinaga, J. Macromol. Sci., Part A: Pure Appl. Chem., 43, 829 (2006).

14. B. S. Kim, J. S. Im, S. T. Baek, J. O. Lee, M. Sigeta, and K. Yoshinaga, Polym. J., 38, 335 (2006).

15. M. Ogawa, K. Kuroda, and T. Nakamura, Chem. Lett., 31, 632 (2002).

16. S. Hamoudi and S. Kaliaguine, Microporous Mesoporous Mater., 59, 195 (2003).

17. M. A. Markowitz, G. Deng, and B. P. Gaber, Langmuir, 16, 6148 (2000).

18. P. Tien, L. K. Chau, Y. Y. Shieh, W. C. Lin, and G. T. Wei, Chem. Mater., 13, 1124 (2001).

19. E. A. de Campos, A. A. da Silva, R. T. Ferrari, and C. M. M. Costa, J. Colloid Interface Sci., 240, 97 (2001).

20. H. Touzi, N. Sakly, R. Kalfat, H. Sfihi, N. Jaffrezic-Renault, M. B. Rammah, and H. Zarrouk, Sens. Actuators, B, 96, 399 (2003).

21. W. Li, D. Fries, A. Alli, and A. Malik, Anal. Chem., 76, 218 (2004).

22. D. W. Grijpma, Q. Hou, and J. Feijen, Biomaterials, 26, 2795 (2005).

23. C. T. Ratnam and K. Zaman, Nucl. Instrum. Methods Phys. Res., Sect. B, 152, 335 (1999).

24. E. Lippmaa, M. Magi, A. Samoson, G. Engelhard, and A.-R. Grimmer, J. Am. Chem. Soc., 102, 4889 (1980).

25. S. Leonardelli, L. Facchini, C. Fretigng, P. Tougne, and A. P. Legrand, J. Am. Chem. Soc., 114, 6412 (1992).

26. D. W. Sindorf and G. E. Maciel, J. Am. Chem. Soc., 103, 4263 (1981). 